\title{
MARVINSKETCH E KAHOOT COMO FERRAMENTAS NO ENSINO DE ISOMERIA
}

\author{
C. H. C. $\operatorname{COSTA}^{1^{*}}$, F. F. DANTAS FILHO ${ }^{2}$ e F. M. G. S. C. MOITA ${ }^{2}$ \\ ${ }^{1}$ Instituto Federal de Educação, Ciência e Tecnologia do Rio Grande do Norte \\ ${ }^{2}$ Universidade Estadual da Paraíba \\ carlos.chaves@ifrn.edu.br* \\ Submetido 19/06/2016 - Aceito 02/02/2017 \\ DOI: 10.15628/holos.2017.4733
}

\section{RESUMO}

O conteúdo de isomeria na Química orgânica ainda é pouco discutido em pesquisas na área de ensino, entretanto os alunos apresentam dificuldades na aprendizagem e visualização espacial dos compostos. 0 presente trabalho trata-se de uma proposta de ensino utilizando as ferramentas colaborativas MarvinSketch e Kahoot buscando minimizar as dificuldades de aprendizagem e motivar os estudantes no aprendizado dos conceitos de isomeria. Foi aplicada uma proposta didática para o estudo dos isômeros, complementada por uma atividade gamificada, no total de $4 \mathrm{~h}$ /aula onde o público alvo foi composto por 27 alunos do 2 ㅇ ano do ensino médio do Instituto Federal do Rio Grande do
Norte (IFRN) campus Caicó. A coleta de dados foi realizada através de um questionário aplicado aos alunos para avaliação da proposta didática. Os resultados obtidos foram positivos em relação a motivação dos alunos para o uso das ferramentas e a contribuição no processo de ensino. Após a análise dos dados obtidos, concluímos que o estudo apontou para a potencialidade destas ferramentas para promover uma melhoria na aprendizagem mediada pela construção e visualização de estruturas e o envolvimento dos estudantes ao participarem de uma atividade gamificada.

PALAVRAS-CHAVE: Ensino, Química, Isomeria, MarvinSketch, Kahoot.

\section{MARVINSKETCK AND KAHOOT AS TOOLS IN THE TEACHING OF ISOMERISM}

\begin{abstract}
The isomer content in Organic Chemistry is still little discussed in researches in the Education area, however the students present difficulties in learning and spatial visualization of the compounds. The present work deals with a proposal of teaching using the collaborative tools MarvinSketch and Kahoot, seeking to minimize the difficulties of learning and to motivate students in learning the concepts of isomerism. It was a didactic proposal for the isomers' study, complemented by a gamified activity, in a total of four lesson hours; where the target audience consisted of 27 students of 2 nd year of high school at
\end{abstract}

\begin{abstract}
Instituto Federal do Rio Grande do Norte (IFRN)/ Campus Caicó. The data were collected through a questionnaire applied to students in order to evaluate the didactic proposal. The results obtained were positive concerning to the students' motivation in the use of the collaborative tools and the contribution in the teaching process. After the data obtained analysis, we conclude that the study pointed to the potential of these tools to promote an improvement in learning mediated by the construction and visualization of structures and the involvement of students to participate in a gamified activity.
\end{abstract}

KEYWORDS: Education, Chemistry, Isomerism, MarvinSketch, Kahoot. 


\section{INTRODUÇÃO}

O desenvolvimento tecnológico que há algumas décadas está transformando significativamente as relações humanas com os seus mais diversos recursos cria novas situações e condições para a prática educativa. A inserção das tecnologias informacionais na educação tem sido objeto de interesse de pesquisadores de variadas áreas do conhecimento. Na educação, cada vez mais, as Tecnologias da informação e comunicação (TIC) assumem papel relevante e merecem estudos investigativos que mostrem sua influência, incorporação e potencial educativo nos processos pedagógicos.

O professor há muito tempo deixou de ser a única fonte de conhecimento da disciplina para os alunos do ensino médio, uma vez que tais alunos fazem uso de uma diversidade de informações disponíveis na internet como por exemplo as vídeo-aulas. Segundo Tardif (2011) o saber experiencial dos docentes pode ser formado por um saber interativo, construído a partir das relações professor - aluno em sala de aula, e um saber prático usado em sua atuação profissional e sua postura perante as situações, problemas e desafios característicos de sua atuação profissional. Conforme visto acima o professor deve pensar o seu conhecimento prático em virtude das tecnologias e diversas fontes de informação disponíveis para o aluno e como isso pode auxiliar a uma melhor interação em sala de aula influenciando no processo de ensino aprendizagem.

De acordo com Silva Júnior e Bizerra (2015), os alunos têm dificuldades de aprendizagem atribuído a falta de motivação nas aulas de Química principalmente quando esse conhecimento é trabalhado sem uma contextualização adequada e sem uma abordagem interdisciplinar. A persuasão pode ser definida como a arte de convencer o outro e podemos observar que o nosso modelo de escola encontra-se apoiado no poder da palavra e como ela é capaz de fazer o aluno aprender alguma coisa (TARDIF, 2011). Devemos buscar alternativas ao discurso do professor para motivar os discentes no aprendizado de Química para isso os docentes precisam explorar as relações dessa ciência com outras disciplinas e procurar metodologias que tenham a interação e a participação do aluno como ideia fundamental.

O tema isomeria ainda é pouco discutido por pesquisas na área de ensino de química, entretanto alguns trabalhos expõem as dificuldades de alunos em relação a aprendizagem e a visualização espacial em estereoisomeria (NETO; CAMPOS; MARCELINO, JÚNIOR 2013). A elaboração de metodologias de ensino que utilizem modelos concretos de estruturas orgânicas ou modelos produzidos por programas de simulação tem sido pesquisado por alguns autores como Giordan e Gois (2009). A revisão de conceitos em uma aula de Química pode ajudar os estudantes na construção do conhecimento, principalmente se estes estiverem motivados durante o processo que pode ser mediado por um "quiz game" chamado Kahoot por exemplo.

Este trabalho objetiva analisar as percepções dos estudantes ao trabalharem com as ferramentas MarvinSketch e Kahoot como facilitadores e motivadores no estudo de isomeria na química orgânica. 


\section{REVISÃO BIBLIOGRÁFICA}

Vivemos em uma sociedade digital onde as pessoas podem estar conectadas à internet por vários dispositivos como telefones celulares, tabletes e computadores, onde o usuário tem acesso a informação e utiliza vários programas e aplicativos disponíveis. Podemos dizer que o avanço da tecnologia permitiu um maior acesso aos dispositivos digitais que hoje estão presentes em várias escolas, como por exemplo no laboratório de informática, e que os Parâmetros Curriculares Nacionais ( $\mathrm{PCN})$ e ( $\mathrm{PCN}+$ ) destacam a importância da utilização da tecnologia no ensino de Ciências. Mas o uso da tecnologia em si é garantia de uma boa aula e de que ocorra aprendizado por parte do aluno? A resposta é não pois a tecnologia não é a aula em sua totalidade e sim apenas uma ferramenta diferenciada para ser usada no processo de ensino aprendizagem (KARNAL, 2014).

Existem alguns programas para construção de gráficos e moléculas dentre eles temos o MarvinSketch (https://www.chemaxon.com/download/marvin-suite/\#mbeans) que foi criado para desenhar estruturas e reações químicas, desenvolvido pela empresa Chemaxon, e com uma versão gratuita disponível para ser salva e executada pelo usuário. O programa é compatível com os principais sistemas operacionais do mercado como Windows, Macintosh e Linux e permite a importação e exportação de arquivos para outros softwares como o Microsoft Word e PowerPoint. Ao construir estruturas o usuário pode indicar cargas eletrônicas em determinados átomos ou grupos; fazer o ajuste da estrutura para uma visualização em 2 ou 3 dimensões; construir os componentes e detalhes de uma reação química com a possibilidade de utilizar isótopos atômicos. Ao usarmos o programa em nossa pesquisa direcionamos os alunos a construírem estruturas com as suas respectivas nomenclaturas e relacionarmos aos tópicos de isomeria abordados. Na figura 1 abaixo mostramos a visualização básica do programa com a estrutura da cafeína construída.

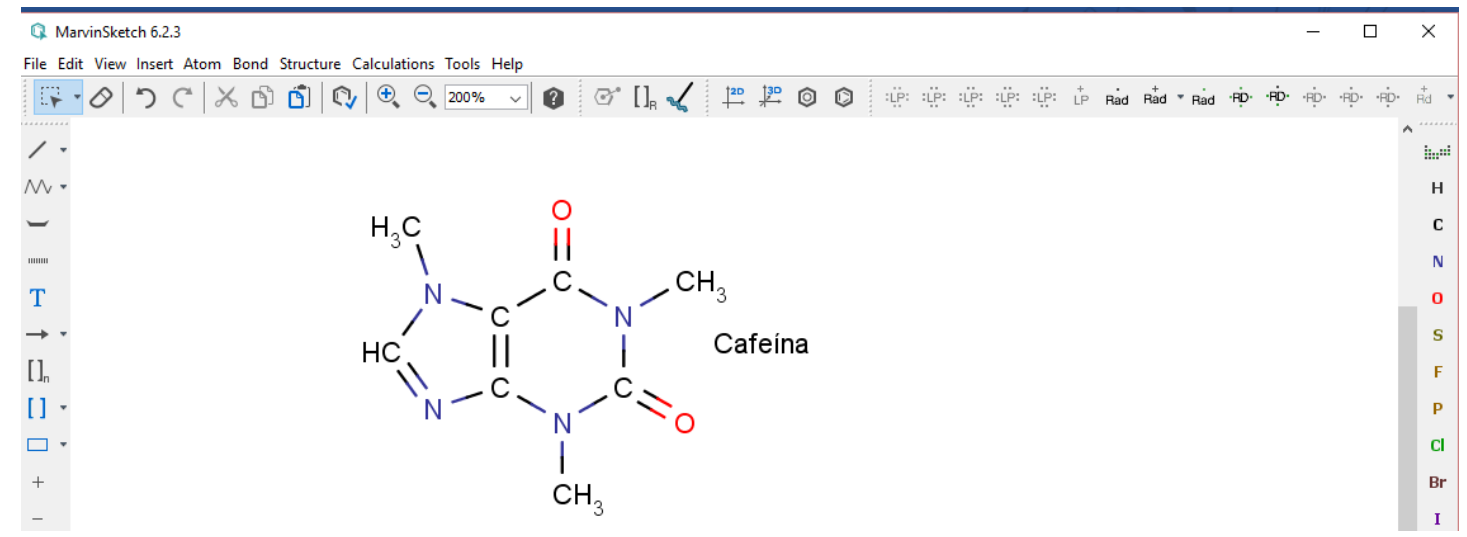

Figura 1: Interface do programa Marvin Sketch.

Fonte: https://www.chemaxon.com/download/marvin-suite/\#mbeans

O jogo pode ser encarado como uma alternativa metodológica para superar dificuldades de ensino aprendizagem em Química pois os mecanismos encontrados nos jogos podem atuar como um fator motivacional do indivíduo em um contexto de uma tarefa a ser realizada (FADEL, 2014). A Gamificação utiliza, em uma realidade fora de jogo, o pensamento, as estratégias e as regras presentes no ato de jogar. Para aplicarmos a gamificação em uma situação de ensino devemos destacar os elementos personagem, competição e regras do jogo; o aluno 
assumirá o papel de personagem; a competição beneficiará a concentração durante a atividade e as regras ajudam na motivação do aluno no processo de aprendizagem (SCHMITZ et al.; 2012). Mais por que o aluno se torna motivado em uma atividade gamificada? A resposta pode estar relacionada ao fato de que ao estar participando de uma atividade gamificada, o aluno pode atingir o estágio de "Flow".

De acordo com Mihaly (1990 apud Fadel, 2014, p. 46): 'Flow' é "a forma como as pessoas descrevem seu estado de espírito quando a consciência está harmoniosamente ordenada e elas querem seguir o que estão fazendo para seu próprio bem". Em sala de aula durante a pratica pedagógica podemos fornecer elementos para que nossos alunos atinjam o estágio acima descrito desde que a atividade gamificada proposta seja capaz de: a) provocar uma maior concentração do aluno durante a atividade; b) provocar uma sensação de êxtase; c) provocar o uso de habilidades; d) provocar a perca de sensação de tempo; e) gerar uma motivação intrínseca em permanecer na atividade (FADEL, 2014). Quanto maior o envolvimento dos alunos em um processo gamificado, maiores serão as chances de que o aluno alcance o estágio de "flow" e que essa metodologia possa contribuir no processo de ensino aprendizagem.

O Kahoot é uma plataforma de aprendizado baseada em jogos disponível em (https://getkahoot.com/). Com o programa é possível criarmos um questionário, uma discussão ou uma pesquisa que será respondida por usuários que estejam conectados à internet por meio de computadores, tabletes ou smartphones. Como atividade de sala de aula pode fazer um questionário (por exemplo, 5 perguntas) em que as perguntas terão uma alternativa correta e enviarmos um código (PIN) para que os alunos participem do jogo. Uma vez iniciada a atividade as perguntas serão controladas pelo professor e no dispositivo do estudante (ou grupo de alunos) apareceram as respectivas alternativas que os participantes após realizarem a leitura terão que indicar a alternativa correta. Os critérios de pontuação são o número acertos e o tempo gasto para responder à pergunta. Ao usarmos o Kahoot no estudo da isomeria espera-se a realização de uma atividade gamificada, onde os alunos sejam motivados. A figura 2 abaixo mostra a tela básica do kahoot durante uma pergunta.

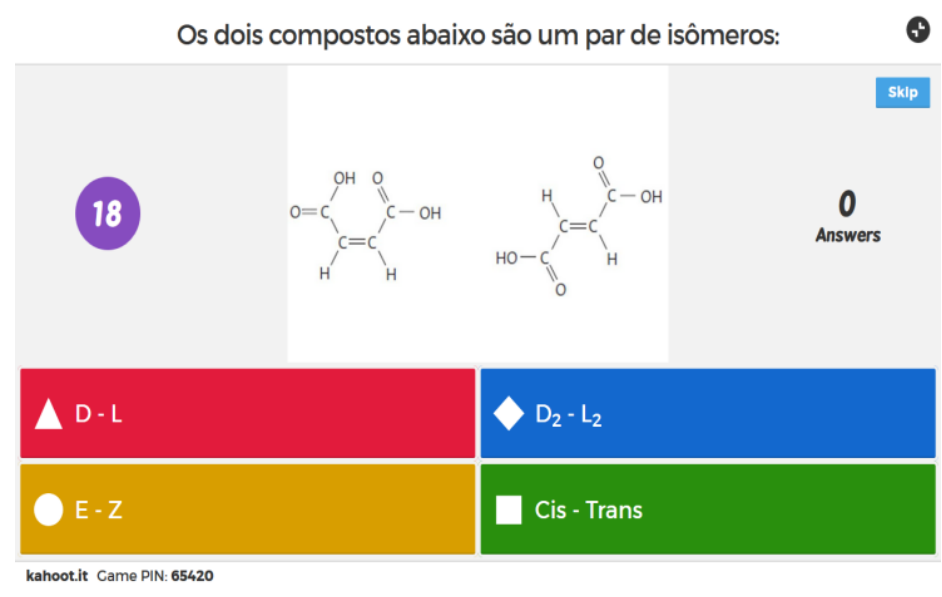

Figura 2: Interface do Kahoot durante a sua aplicação. Fonte: https://play.kahoot.it/\#/?quizld=da036686-671d4116-b1c4-fbd687221143

Historicamente o estudo da isomeria na química teve início a partir de semelhanças em dois trabalhos relacionados a descoberta de um novo composto, com formula molecular AgCNO, mas com propriedades diferentes enviados a J. J. Berzelius (1779 - 1848), em 1830 (NETO; 
CAMPOS; MARCELINO, JÚNIOR 2010). Após vários estudos, Berzelius confirmou a veracidade dos dois trabalhos e notou a probabilidade de se obter dois compostos com propriedades químicas e físicas diferentes que possuem a mesma contagem atômica em sua formula molecular. Atualmente podemos dividir os isômeros em dois grandes grupos: Isomeria constitucional - onde os compostos apresentam seus átomos conectados em ordens diferentes (fato observado na nomenclatura relacionada a fórmula estrutural) e Estereoisomeria com estruturas onde os átomos estão conectados na mesma ordem, mas possuem arranjo diferente no espaço (geométrica) e com estruturas onde há a presença de um carbono tetraédrico capaz de desviar o plano da luz polarizada (óptica) (SOLOMONS, 2000). A isomeria não é um fenômeno exclusivo dos compostos orgânicos pois está presente também em compostos inorgânicos.

\section{METODOLOGIA}

\subsection{Abordagem Metodológica}

A pesquisa tem natureza quali-quantitativa, entende-se pela abordagem qualitativa que ele tem natureza descritiva, pois esta possibilita o conhecimento do fenômeno como um todo, utilizando o método indutivo, processo mental em que o indivíduo parte de dados particulares vistos com certa repetição, como afirma Xavier (2012). Enquanto o enfoque quantitativo se traduz em dados quantitativos para classifica-los e organizá-los, utilizando métodos estatísticos, com a representação dos resultados, geralmente em gráficos (GIL, 2008). Concomitantemente, desenvolve-se a pesquisa com uma análise da construção de conhecimento mediado por interfaces virtuais, pois possibilita ao processo de ensino-aprendizagem, obtendo como produto final um material didático dinâmico que motive os sujeitos professor-aluno e os auxilie no exercício da docência.

\subsection{População e Amostra}

Nesta pesquisa, o público alvo foi composto por alunos do 20 ano do curso de Eletrotécnica na forma integrada do Instituto Federal do Rio Grande do Norte (IFRN) Campus Caicó da qual participaram 27 alunos durante o período de 4 horas aula.

\subsection{Descrição da proposta Didática}

A investigação teve como etapa inicial a definição do conceito de isomeria na química orgânica com a visualização de formulas moleculares e estruturais, com a mesma contagem atômica e com diferenças nas posições dos átomos. Foram discutidos o conceito de isomeria constitucional e o reconhecimento de isômeros a partir das nomenclaturas. A etapa conceitual foi finalizada com a abordagem dos conceitos de isomeria espacial geométrica (Cis-Trans e E-Z) e espacial óptica pelo desvio da luz polarizada.

$\mathrm{Na}$ etapa posterior foram demonstradas as ferramentas básicas de construção, nomenclatura e visualização de estruturas em 2 e 3 dimensões do programa MarvinSketch em seguida foi proposto aos alunos a construção das seguintes estruturas:

A - 2-metilbutano e pentano com o objetivo de relacionar a isomeria plana;

B - 2 - cloro - 3-flúorpent-2-eno com o objetivo de relacionar a isomeria geométrica; 
C - Ácido - 2- hidroxipropanóico com o objetivo de relacionar a isomeria óptica;

Com o objetivo de revisar conceitos discutidos na proposta didática foi aplicado o "quizgame" Kahoot que foi iniciado com o cadastro dos alunos mediante o código de acesso (PIN) e escolha do nome das equipes onde os alunos se dividiram em 7 grupos. As perguntas foram elaboradas e editadas no Kahoot e estavam relacionadas ao conteúdo de isomeria visto nas etapas expositiva e prática realizada no MarvinSketch, com 15 perguntas de múltipla escolha com 4 alternativas (Ver anexo A) e tempo de resposta entre 30 e 120 segundos (maior tempo para perguntas de maior dificuldade). Após cada pergunta foi dado um retorno aos alunos sobre as respostas e abordagem de conceitos.

\subsection{Instrumentos de coleta de dados}

Como instrumento de coleta de dados foi aplicado o questionário com 10 perguntas do tipo aberta e semiestruturada respondido pelos alunos em um formulário GoogleDocs que forneceria dados sobre a aplicação da proposta didática. O Kahoot também fornece dados dos alunos que participaram do "quiz-game".

\section{RESULTADOS E DISCUSSÃO}

Na etapa de exposição de conceitos sobre Isomeria houve muita participação dos alunos que fizeram questionamentos sobre os tópicos de isomeria constitucional (plana) e a isomeria óptica a partir do conceito de carbono quiral. Foi observado que os alunos não sentiram dificuldade em construir as estruturas e ficaram impressionados com os recursos fornecidos pelo programa MarvinSketch. Os isômeros constitucionais, geométricos (E-Z) e ópticos propostos para serem construídos com o software Marvin se encontram presentes na figura 3 abaixo.

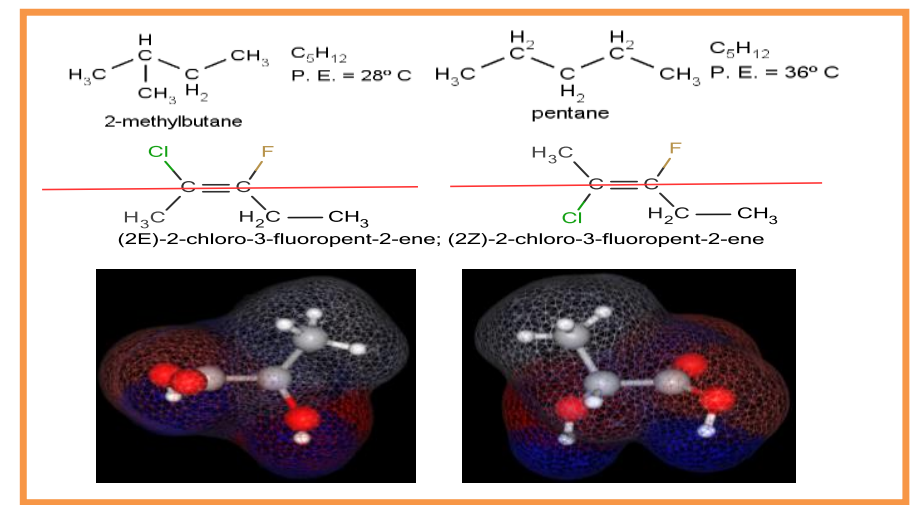

Figura 3: Estruturas construídas com o software MarvinSketch. Fonte: Autoria própria

A escolha do tema Isomeria e da ferramenta MarvinSketch baseou-se nas observações e vivencias com a prática pedagógica no ensino de química orgânica, a qual mostrou que uma das dificuldades encontradas no processo da aprendizagem é montagem da estrutura espacial sendo essa fundamental para a diferenciação de estruturas com a mesma formula molecular. Segundo os autores Wu e Shah (2004), um ponto crítico no ensino de isomeria consiste na identificação dos isômeros geométricos pois os estudantes precisam transformar a fórmula química em sua estrutura molecular, visualizar a possível configuração tridimensional e comparar as estruturas. De acordo com os autores Keig e Rubba (1993) a representação tridimensional, importante para 
a compreensão dos diferentes isômeros geométricos, não é dominada por todos os estudantes em especial a transição 2D (fórmula estrutural plana) para 3D (forma geométrica).

A aplicação do "quiz-game" Kahoot na forma de atividade gamificada teve uma boa aceitação dos alunos, observou-se que em cada grupo havia muita agitação para a escolha da resposta correta e motivação para participar da atividade (fala de um aluno: "vamos lá professor a próxima pergunta..."). Quando todas as equipes respondiam ou o tempo de resposta se esgotava os alunos ficavam atentos para o resultado de erros ou acertos onde cada equipe demonstrava seus sentimentos em função dos resultados alcançados conforme podemos ver na figura 4 abaixo.

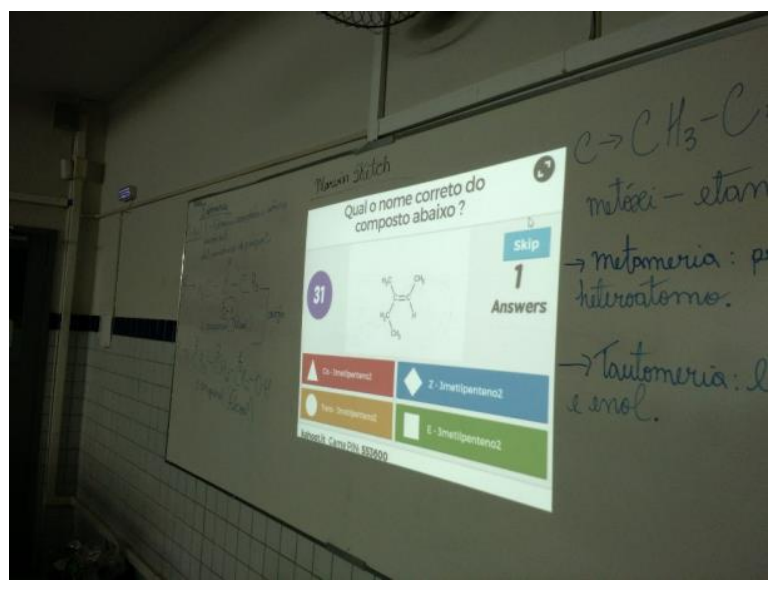

a)

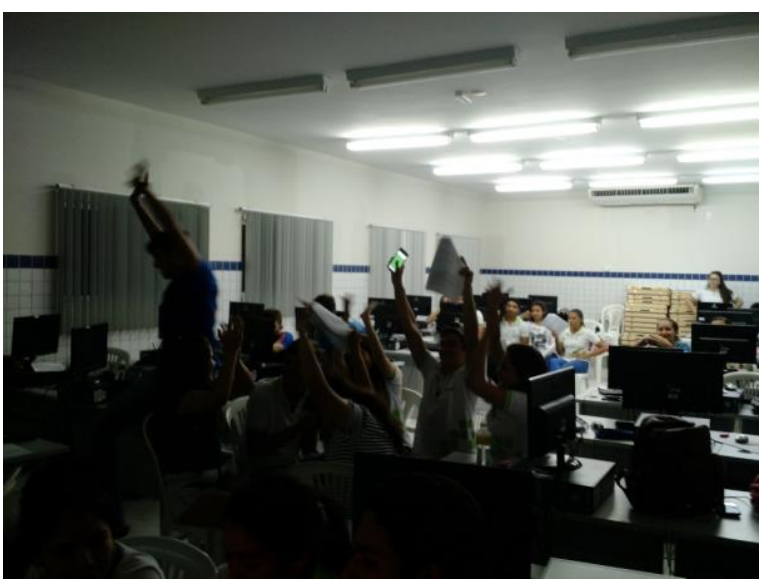

b)

Figura 4: Aplicação do Kahoot - a) Questão sendo respondida; b) reação dos alunos com as respostas. Fonte: Autoria própria

Não podemos afirmar precisamente se os alunos participantes alcançaram ou não o estágio de "flow" definido por Mihaly (1990), mas pudemos observar que os elementos como concentração dos alunos, uso de habilidades, sensação de êxtase e envolvimento dos discentes no processo estavam presentes durante a atividade gamificada. Ao final da aplicação o kahoot fornece os resultados dos grupos participantes que podem ser salvos em "nuvem" (google drive) ou serem exportados na forma de uma planilha, onde a tabela 1 abaixo apresenta o resumo de desempenho dos grupos participantes.

Tabela 1: Desempenho dos grupos ao responderem o quiz game Kahoot.

\begin{tabular}{c|c|c|c|c}
\hline Grupo & $\begin{array}{c}\text { Respostas } \\
\text { corretas }\end{array}$ & Respostas incorretas & Placar final & Desempenho Geral \\
\cline { 1 - 3 } Amélia & 10 & 5 & 9110 & \% respostas corretas: 45 \\
\cline { 1 - 3 } Zorua & 7 & 8 & 6196 & \\
\hline GG WP IZI & 7 & 8 & 6086 & \% respostas incorretas: 55 \\
\cline { 1 - 3 } Track & 7 & 8 & 5889 & \\
\cline { 1 - 3 } AAFM & 6 & 8 & 3638 & \multirow{2}{*}{ Placar médio: 5466} \\
\hline Pikakatchu & 4 & 11 & 1958 & \\
\hline Jesus & 2 & 4 &
\end{tabular}


De acordo com os dados da Tabela 1, o número de respostas incorretas supera as corretas, este fato foi atribuído a ausência de respostas de alguns participantes, devido a problemas de conexão e não responderem as questões dentro do tempo estabelecido. Ao verificarmos a quantidade de acertos por questões presentes na Tabela 5 (Anexo A) observamos que os sujeitos pesquisados sentiram dificuldade em aprender e identificar as estruturas em 3 dimensões e a isomeria óptica. Corroborando com as pesquisas realizadas por Wu e Shah (2004) e Keig e Rubba (1993). Diante desta observação, sugerimos aos docentes que ao aplicar esta proposta de ensino, trabalhem mais os conceitos relacionados as fórmulas estruturais dos compostos orgânicos e isomeria facilitando os alunos a compreensão dos mesmos.

Nas respostas do formulário GoogleDocs conseguimos como resultado nas questões objetivas que dos 27 alunos 55,6 \% eram do sexo feminino e 44,4 \% eram do sexo masculino com idade variando entre 16 e 19 anos; $100 \%$ dos alunos tinham computador em suas residências e destes $92,6 \%$ com acesso à internet. Perguntamos a opinião dos alunos sobre o uso dos programas MarvinSketch e Kahoot nas aulas de isomeria e a contribuição para o aprendizado do conteúdo onde as respostas foram submetidas a análise de conteúdo da autora Bardin (1997) e cujo os resultados se encontram nas tabelas 2, 3 e 4 abaixo.

Tabela 2: Pergunta 01 - 0 que você acha de utilizar o computador e um software educativo nas aulas de Química Orgânica (Isomeria)?

\begin{tabular}{|c|c|c|}
\hline Respostas & $\%$ & Fala dos Sujeitos \\
\hline $\begin{array}{l}\text { 1. A proposta teve boa aceitação } \\
\text { pelos alunos. }\end{array}$ & $25,93 \%$ & "Gostei da ideia ajudou muito". \\
\hline $\begin{array}{l}\text { 2. A proposta motivou o aluno a se } \\
\text { concentrar na aula e no conteúdo } \\
\text { estudado. }\end{array}$ & $29,63 \%$ & $\begin{array}{l}\text { "Muito bom chama a atenção do aluno para o } \\
\text { assunto". }\end{array}$ \\
\hline $\begin{array}{l}\text { 3. A proposta tornou a aula mais } \\
\text { eficiente e contribuiu para o } \\
\text { aprendizado do aluno. }\end{array}$ & $37,04 \%$ & $\begin{array}{l}\text { "Muito produtivo, torna aula mais divertida e } \\
\text { bem mais eficiente, economiza tempo e ajuda na } \\
\text { maior compreensão". }\end{array}$ \\
\hline 4. A proposta foi criativa. & $7,4 \%$ & "Bastante criativa". \\
\hline
\end{tabular}

Tabela 3: Pergunta 02 - De que forma o programa Marvin Sketch contribuiu para o seu aprendizado do conteúdo de isomeria?

\begin{tabular}{|c|c|c|}
\hline Respostas & $\%$ & Fala dos Sujeitos \\
\hline $\begin{array}{l}\text { 1. O programa melhorou a } \\
\text { compreensão do assunto. }\end{array}$ & $25,93 \%$ & "Deu um maior entendimento ao assunto". \\
\hline $\begin{array}{l}\text { 2. O programa contribuiu para a } \\
\text { visualização e compreensão das } \\
\text { estruturas moleculares. }\end{array}$ & $51,85 \%$ & $\begin{array}{c}\text { "A visualizar melhor e entender as estruturas } \\
\text { moleculares". }\end{array}$ \\
\hline $\begin{array}{l}\text { 3. A programa auxilia na } \\
\text { compreensão e estimula o aluno a } \\
\text { aumentar seus conhecimentos. }\end{array}$ & $7,41 \%$ & $\begin{array}{c}\text { "Ele ajuda no entendimento do aluno e o } \\
\text { influencia a querer conhecer melhor a } \\
\text { matéria". }\end{array}$ \\
\hline $\begin{array}{l}\text { 4. O programa estimula o exercício } \\
\text { de conceitos. }\end{array}$ & $14,81 \%$ & "Exercitar o assunto". \\
\hline
\end{tabular}


Tabela 4: Pergunta 03 - De que forma o Kahoot contribuiu para o seu aprendizado do conteúdo de isomeria?

\begin{tabular}{l|l|l}
\hline Respostas & $\%$ & Fala dos Sujeitos \\
\hline $\begin{array}{l}\text { 1. Revisão de conceitos } \\
\begin{array}{l}\text { 2. O ambiente de competição } \\
\text { estimula o aprendizado. }\end{array}\end{array}$ & $7,41 \%$ & "Ajudou a revisar os problemas". \\
\hline $\begin{array}{l}\text { 3. As perguntas com tempo } \\
\text { determinado estimulam o } \\
\text { raciocínio rápido. }\end{array}$ & $29,63 \%$ & $\begin{array}{l}\text { "O ambiente de competição estimula a melhora". } \\
\text { pense rápido". }\end{array}$ \\
\hline $\begin{array}{l}\text { 4. A competição estimulou a } \\
\text { concentração dos alunos e o } \\
\text { trabalho em equipe. }\end{array}$ & $11,11 \%$ & $\begin{array}{l}\text { "A exposição das questões em um meio } \\
\text { competitivo, estimula o raciocínio rápido do } \\
\text { aluno testando a sua atenção e o trabalho em } \\
\text { equipe". }\end{array}$ \\
\hline $\begin{array}{l}\text { 5. O programa motivou os alunos a } \\
\text { participarem da aula e foi } \\
\text { considerado um ponto positivo. }\end{array}$ & $14,81 \%$ & $\begin{array}{l}\text { "As perguntas nos deixam mais atentos e } \\
\text { permitem que nós conseguimos captar mais } \\
\text { assuntos". }\end{array}$ \\
\hline $\begin{array}{l}\text { 6. O questionário foi eficiente na } \\
\text { revisão dos conceitos }\end{array}$ & $14,82 \%$ & $\begin{array}{l}\text { "As perguntas foram variadas fazendo com que o } \\
\text { assunto fosse absorvido". }\end{array}$ \\
\hline
\end{tabular}

As tabelas acima mostraram que o uso do computador e dos programas na aula de isomeria tiveram um impacto positivo na motivação, interação e aprendizado dos alunos. Ao criarem estruturas no Software Marvin os alunos puderam esclarecer dúvidas sobre a construção de cadeias carbônicas, nomenclatura dos compostos e uma melhor compreensão de estruturas na visualização espacial. O ambiente de questionário com vários jogadores do Kahoot permitiu a revisão dos conceitos estudados durante a aula e a colaboração entre os alunos nas equipes, onde um ambiente de competição estimulou os alunos para o aprendizado. Cassettari (2015) obteve resultados semelhantes onde $79 \%$ dos alunos responderam concordo ou concordo plenamente em relação a motivação e 81 \% dos alunos concordaram com a contribuição do "quiz-game" Kahoot na aprendizagem.

O uso dos programas Kahoot e MarvinSketch foram essenciais para aprendizagem dos conteúdos sobre Isomeria no ensino médio onde eles auxiliaram o aluno a pensar a respeito de certos conceitos abstratos e contribuíram para a participação dos estudantes na construção das fórmulas dos compostos em 3D. Observou-se também nos estudantes a ação colaborativa, solidariedade, prestatividade, compromisso e responsabilidade social, pilares indispensáveis para a formação de cidadãos críticos. As tecnologias digitais, assim como tantos outros artefatos, são construídas e herdadas no interior do meio social em que se vive. Por extensão, essas tecnologias, tão habilmente manuseadas pelos nativos digitais, não podem e não devem ser ignoradas por aqueles que elaboram estratégias de ensino (PAULETTI; CATELLI, 2013).

\section{CONSIDERAÇÕES FINAIS}

Ao iniciarmos este trabalho tínhamos a intenção de incentivar os nossos discentes para a aprendizagem em Química facilitando o desenvolvimento de suas competências e habilidades necessárias para a resolução de problemas e o aumento da percepção desses jovens em torno das aplicações práticas dessa Ciência na sociedade contemporânea. 
Os resultados obtidos confirmam a receptividade dos estudantes frente ao uso das ferramentas colaborativas MarvinSketck e Kahoot no decorrer da atividade desenvolvida. A utilização das TIC proporcionou aos discentes envolvidos um maior contato com os conceitos químicos pertinentes ao estudo de isomeria e estruturas orgânicas de modo espontâneo e interativo.

É importante ressaltar que a criação de um ambiente favorável à aprendizagem além de incluir a participação ativa dos estudantes, faz necessário o planejamento de atividades que propiciem esse envolvimento. $E$, pelo que percebemos, a atividade com o uso das TIC, usando a ideia de atividade gamificada, é capaz de envolver os estudantes.

A inserção das TIC no ensino de isomeria consiste num desafio para os professores de Química, pois sua utilização só tem eficaz se for crítica e significativa para o processo de ensino e aprendizagem e exige dos professores em formação inicial uma melhor preparação para a utilização das TIC para a prática pedagógica mediada por estes espaços de aprendizagem.

\section{REFERÊNCIAS}

Bardin, L. (1997). Análise de conteúdo (5ª ed.). Lisboa: Edições.

Brasil. Parâmetros Curriculares Nacionais Para o Ensino Médio. Brasília: MEC/SEMTEC, 2002. Recuperado em 15 de abril, 2016, de http://portal.mec.gov.br.

Brasil. (1999). Parâmetros Curriculares Nacionais do Ensino Médio. Brasília: MEC/SESu.

Cassettari, F. T. (2015). Estudo de caso: uso de um quiz game para revisão de conhecimentos em gerenciamento de projetos. Trabalho de Conclusão de Curso, Universidade Federal de Santa Catarina, Florianópolis.

Fadel, L. M. et al. (org.). (2014). Gamificação na educação. São Paulo: Pimenta Cultural. Recuperado em 3 de janeiro, 2016, de https://www.academia.edu/9139616/_eBook__PDF_Gamifica\%C3\%A7\%C3\%A3o_na_Educa\%C3\%A7\%C3\%A3o.

GIL, A. C. (2008). Como elaborar projetos de pesquisa (4. ed.). São Paulo: Atlas.

Giordan, M., Gois, J. (2009) Entornos virtuales de aprendizaje en química: una revisión de la literatura. Educación Química, v. 20, n. 3, pp, 301-303. Recuperado em 15 de março, 2016, de http://www.lapeq.fe.usp.br/textos/te/tepdf/giordan_gois-educacionquimica-2009.pdf.

Karnal, L. (2014). Conversas com um jovem professor (1 ed.). São Paulo: Contexto.

Keig, P. F., Rubra, P. A. (1993). Translation of representations of the structure of matter and its relationship to reasoning, Gender, Spatial Reasoning, And Specific Prior Knowledge. Hoboken (NJ), Journal of Research in Science Teaching, 30, 883-903.

Neto, J., Simões, E., Campos, Â. F., Júnior, M., Cardoso, C. A. (2016). Abordando a isomeria em compostos orgânicos e inorgânicos: uma atividade fundamentada no uso de situações-problema na formação inicial de professores de Química. Revista investigações em ensino de ciências, vol.18, p. 328. Recuperado em 15 de março, 2016, de www.if.ufrgs.br/ienci/artigos/Artigo_ID333/v18_n2_a2013.pdf.

Neto, J., Simões, E., Campos, Â. F., Júnior, M., Cardoso, C. A. (2010). Abordando o conceito de isomeria por meio de situações-problema no ensino superior de química. XV Encontro Nacional de Ensino de Química (XV ENEQ), Brasília, DF. Recuperado em 18 de abril, 2016, de 
http://www.xveneq2010.unb.br/resumos/R0699-2.pdf.

Pauletti, F., Catelli, F. Tecnologias digitais: possibilidades renovadas de representação da química abstrata, Acta Scientiae, 15, 2, pp 383-396, 2013.

Schmitz, B., Klemke, R., Specht, M. (2012). Effects of mobile gaming patterns on learning outcomes: a literature review. Journal Technology Enhanced Learning, p. 9 . Recuperado em 18 de abril, 2016 de https://www.researchgate.net/publication/235265707_Effects_of_mobile_gaming_patterns_on_ learning_outcomes_A_literature_review.

Silva Júnior, C. A. B., Bizerra, A. M. C. (2015). Estruturas e nomenclaturas dos hidrocarbonetos: é possível aprender jogando? Revista Holos, ano 31, vol. 6, p. 147. Recuperado em 15 de março, 2016 de http://www2.ifrn.edu.br/ojs/index.php/HOLOS/article/view/3616/1219.

Solomons, G., Fryhle, C. (2000). Química Orgânica (7. ed.). Rio de Janeiro: Editora Livros Técnicos e Científicos - LTC.

Tardif, M. (2011). Saberes docentes e formação profissional (12. ed.). Petrópolis, RJ: Vozes.

Wu, H.K., Shah, P. (2004). Exploring visuospatial thinking in chemistry learning. Hoboken(NJ), Science Education, 88, 3, 465-492.

Xavier, A. C. (2012). Como fazer e apresentar trabalhos científicos em eventos acadêmicos. Recife: Rêspel. 


\section{ANEXO A}

A Tabela 5 Mostra as questões utilizadas no Kahoot e porcentagem de acerto dos alunos participantes.

Tabela 5: Questões aplicadas no "quiz-game” kahoot e quantidade de acertos.

\begin{tabular}{|c|c|c|}
\hline Questões aplicadas & Alternativas & $\begin{array}{c}\text { Respostas } \\
\text { corretas } \\
(\%) \\
\end{array}$ \\
\hline $\begin{array}{l}\text { 1. Ácido etanóico e metanoato de metila são isômeros } \\
\text { de: }\end{array}$ & $\begin{array}{l}\text { Função; } \\
\text { Cadeia; } \\
\text { Posição; } \\
\text { Geométrica. }\end{array}$ & 71,43 \\
\hline $\begin{array}{l}\text { 2. Qual o tipo de isomeria existente entre as estruturas } \\
\text { abaixo? } \\
\mathrm{H}_{3} \mathrm{C}-\mathrm{N}-\mathrm{CH}_{3} \\
\text { dimetilamina }\end{array}$ & $\begin{array}{l}\text { Função; } \\
\text { Cadeia; } \\
\text { Posição; } \\
\text { Óptica. }\end{array}$ & 0 \\
\hline $\begin{array}{l}\text { 3. As estruturas abaixo possuem diferença em seus } \\
\text { radicais que caracterizam serem isômeros de: }\end{array}$ & $\begin{array}{l}\text { Função; } \\
\text { Cadeia; } \\
\text { Posição; } \\
\text { Óptica. }\end{array}$ & 28,57 \\
\hline 4. Os dois compostos abaixo são um par de isômeros: & $\begin{array}{l}\text { Cis - Trans; } \\
\text { E-Z; } \\
\text { D-L; } \\
\text { D2 - L2 }\end{array}$ & 83,33 \\
\hline 5. Qual o nome do composto abaixo? & $\begin{array}{l}\text { Z-3 metil penteno-2; } \\
\text { E-3 metil penteno- } 2 \text {; } \\
\text { Cis-3 metil penteno- } 2 \text {; } \\
\text { Trans-3 metil penteno- } 2 \text {. }\end{array}$ & 33,33 \\
\hline $\begin{array}{l}\text { 6. Quantos Carbonos assimétricos e isômeros ópticos } \\
\text { ativos a figura abaixo possui? }\end{array}$ & $\begin{array}{l}3 \text { e } 8 \\
4 \text { e } 16 \\
2 \text { e } 4 \\
1 \text { e } 2\end{array}$ & 0 \\
\hline $\begin{array}{l}\text { 7. Quantos isômeros ópticos ativos e inativos a estrutura } \\
\text { abaixo possui? }\end{array}$ & $\begin{array}{l}2 \text { e } 1 \\
2 \text { e } 2 \\
4 \text { e } 2 \\
8 \text { e } 4\end{array}$ & 0 \\
\hline
\end{tabular}


8. Qual o tipo de isomeria mostrado abaixo?

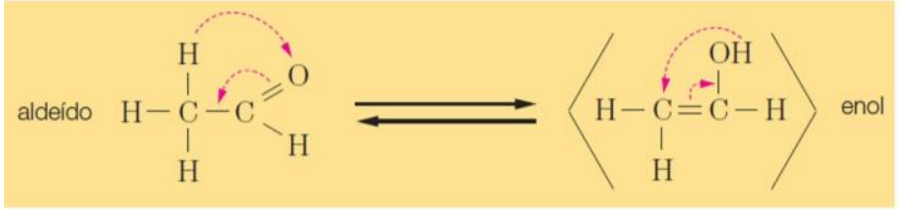

9. Marque a alternativa em que os compostos apresentam isomeria espacial:

I-2-buteno

II-1-penteno

III-ciclopentano

IV-1,2-dicloro-ciclobutano

10. A formula $\mathrm{C}_{4} \mathrm{H}_{8}$ possui alguns isômeros. A sequência correta de cima para baixo é:

$$
\begin{gathered}
\mathrm{H}_{3} \mathrm{C} \\
\mathrm{H}_{2} \mathrm{C}-\mathrm{CH}_{3} \\
\mathrm{H}_{2} \mathrm{C}-\mathrm{CH}_{2}
\end{gathered}
$$

11. O par de compostos abaixo possui a isomeria do tipo:

$$
\begin{aligned}
& \mathrm{H}_{3} \mathrm{C}-\mathrm{O}-\mathrm{C}-\mathrm{C}-\mathrm{C}-\mathrm{CH}_{3} \\
& \text { metoxipropano } \\
& \mathrm{H}_{3} \mathrm{C}-\underset{\mathrm{H}_{2}}{\mathrm{C}}-\mathrm{O}-\mathrm{H}_{2}-\mathrm{CH}_{3}
\end{aligned}
$$

12. Quantos isômeros estruturais e geométricos são previstos com a formula $\mathrm{C}_{3} \mathrm{H}_{5} \mathrm{Cl}$ ? secundário do butano resulta em um isômero do:

Tautomeria;

83,33

Metameria;

Cis - Trans;

E-Z.

$1,2,3,4$

$2,1,4,3$;

$1,3,2,4$;

$3,2,1,4$.

II e III;

I e IV;

II e IV.

\section{Tautomeria;}

83,33

Metameria;

Cadeia;

Função.

2 ;

5

3 ;

4.

2-metilbutano;

2-metilpentano;

3-metilpentano;

hexano.

14. Em relação as substâncias I e II assinale a alternativa correta?<smiles>CC[C@H](C)O</smiles><smiles>CCC(C)C</smiles>

II

15. Isômeros são compostos:

De mesma formula molecular e estrutural;

De mesma formula estrutural e molecular diferentes;

De mesma formula molecular e estrutural diferentes;

Mesma formula mínima. 